\title{
Telemedical assistance at sea in the time of COVID-19 pandemic
}

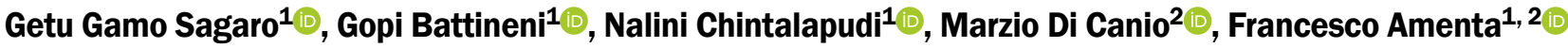 \\ ${ }^{1}$ Telemedicine and Telepharmacy Centre, School of Medicinal and Health Products Sciences, University of Camerino, Italy \\ ${ }^{2}$ Research Department, International Radio Medical Centre (C.I.R.M.), Rome, Italy
}

\begin{abstract}
Background: Severe acute respiratory syndrome coronavirus 2 (SARS-CoV-2), the aetiological factor of COVID-19 infection, poses problems in providing medical assistance at sea. Ships are in an isolated environment, and most of the merchant ships do not carry medical personnel or medical supplies. Telemedicine offers a real possibility to provide reasonable quality medical assistance to seagoing vessels. The fact that ships may touch ports in affected areas, the difficulties for seafarers to be assisted ashore due to quarantine measures and the crews' lack of turnover make medical assistance at sea difficult. This study has compared maritime telemedical assistance data before and during the COVID-19 pandemic to propose prevention measures.

Materials and methods: The study was based on the data from medical records of Centro Internazionale Radio Medico (C.I.R.M.) database of seafarers assisted from January 1 to June 30, in the years 2017-2020. The data were collected separately for each year. Age, sex, rank, and pathologies affecting the assisted seafarers were considered. Common signs of COVID-19 infection such as fever, cough, sore throat, shortness of breath, and other respiratory symptoms were analysed.

Results: From January 1, 2017, to December 31, 2019, C.I.R.M. assisted 15,888 patients on board ships. During the first 6 months of the years under evaluation, C.I.R.M. assisted 2,419 patients in 2017, 2,444 patients in 2018,2,694 patients in 2019, and 3,924 in 2020. The number of assisted cases almost doubled in the first 6 months (from January to June) of 2020 compared to the same period of the previous years. Gastrointestinal disorders, injuries/traumas, and dermatological pathologies were the first, second, and third most often reported causes of illness on board over the 4-year study period. A higher number of seafarers with fever, cough, sore throat, and shortness of breath were assisted during the COVID-19 pandemic than before the coronavirus outbreak. Medical requests for fever increased significantly during the COVID-19 pandemic compared to the same period from 2017 to 2019.

Conclusions: The requests for medical advice for fever, sore throat, and shortness of breath were significantly more common during the coronavirus epidemic. Close follow-up, regular health education on preventing coronavirus transmission, personal protective equipment, adequate environmental hygiene, and applying other standard precautions could help minimise the risk factors for the spread of COVID-19.
\end{abstract}

(Int Marit Health 2020; 71, 4: 229-236)

Key words: COVID-19 pandemic, seafarers, medical advice, infection

\section{INTRODUCTION}

Coronavirus is the member of a large family of viruses causing several pathologies affecting the pulmonary system ranging from the common cold to severe respiratory syndromes such as the Middle East respiratory syndrome (MERS) and the severe acute respiratory syndrome (SARS) [1]. SARS-CoV-2, which is also called novel coronavirus, originated from Wuhan City in China [2]. Globally, until May 31, 2020, $5,934,936$ cases were registered with 367,166 deaths [3]. Despite the apparent reduction in the number of COVID-19 cas- 
es, the fact that there is no medication or vaccine for this deadly and highly transmissible virus makes this medical emergency still a serious issue worldwide.

It is far more challenging and difficult to treat the COVID-19 on board a ship than ashore. Ships at sea are an example of isolated communities, and the fact that the majority of cargo ships do not carry doctors or adequately trained paramedics makes the possibilities of intervention more difficult. The shipping sector carries $90 \%$ of global trade and is the main artery of international supply chains. It was reported that in April 2020, the volume of global merchandise trade was decreased by approximately $13 \%$, and there are estimates of a $25 \%$ reduction in shipping, with a forecast of $10 \%$ annual fall of maritime traffic in 2020 [4].

The situation on the cruise ship Diamond Princess is a perfect illustration of the difficulties in providing medical assistance on board a ship during the COVID-19 outbreak. The Diamond Princess is a British registered cruise ship that arrived offshore of Yokohama port on the evening of February 3 (Monday), 2020 and on that day the quarantine began [5]. There were 2,666 passengers and 1,045 crew members on board of the ship (a total of more than 3,700 ), and even though the ship had medical facilities on board and was assisted by the Japanese Health authorities, the quarantine lasted until February 20, and 619 of 3,700 passengers and crew members (17\%) were tested positive [6]. Despite the discussions about the effectiveness of public health countermeasures taken on that occasion, the situation demonstrates how problematic it is to manage epidemic situations on board a ship [6].

The COVID-19 pandemic represents a serious problem for seafarers. From an organisation's point of view, seafarers have to face considerable problems joining and leaving their ships in ports (each month, around 100,000 seafarers are involved in crew changes). The prohibition, or at least delays in being allowed to return home, the extension of tours of duty with the consequent fatigue caused by an increased workload, isolation, and social pressures for seafarers due to forced separation from their families, all increases distress among seafarers. The pandemic also has a direct influence on the health condition of seafarers. There are quarantine restrictions for international seafarers on being able to go ashore for medical treatment or access portbased welfare services as well as restrictions on the delivery to ships of essential medical supplies, in cases where ships are refused entry into ports [4].

The problem of providing medical care on board ships not carrying a doctor has always been a significant challenge. Since the first license of a radio medical service for seafarers issued by the State of New York (the USA) on November 18, 1920, several radio medical services have been operational, starting with radio signals and Morse code, evolving through telephones to full-blown telemedicine solutions [7]. In addition to all the challenges facing telemedicine for users and providers on land, several are to be met at sea. Technological limitations and organisational challenges are abundant, but we also have significant medical challenges [8]. At present, telemedicine offers the best possibility to provide medical assistance to ships without a doctor on board, although obviously it has its downfalls [7].

In view of both health and organisational problems experienced by seafarers due to the diffusion of COVID-19, e.g. closure of ports, etc., we have decided to analyse the impact of the pandemic on telemedical advice requests to the Centro Internazionale Radio Medico (C.I.R.M.). C.I.R.M. is the Italian Telemedical Maritime Assistance Service (TMAS) [9], and with more than 100,000 patients assisted on board ships, it represents the TMAS with the largest experience of medical assistance at sea in the world.

The present study has analysed the C.I.R.M. medical assistance data generated in the period from January 1 , 2017 to December 31, 2019 used as a reference, and subsequently the data of medical assistance from January 1 , 2020 to June 30, 2020. The starting date of January 1 , 2020 was chosen since, on December 31, 2019, the World Health Organization (WHO) China Country Office was informed of cases of pneumonia of unknown aetiology in Wuhan City, Hubei Province of China.

\section{MATERIALS AND METHODS}

This retrospective study has analysed the C.I.R.M. data of seafarers assisted from January 1 to June 30 during the years 2017-2020. The data were collected separately for each year. Age, sex, rank, and pathologies reported by the assisted seafarers were considered. Common signs of COVID-19 infection such as fever, cough, sore throat, shortness of breath, and other respiratory symptoms were also analysed.

Medical conditions reported by seafarers were classified according to the International Statistical Classification of Diseases and Related Health Problems $10^{\text {th }}$ Revision [10]. The data were analysed by descriptive statistics, including mean, median, and standard deviation for continuous variables. The $\chi^{2}$ or Fisher tests were used for assessing the significance of differences between patients reporting the signs of COVID-19 before and during the COVID-19 pandemic. A two-tailed p-value less than 0.05 was considered statistically significant, and the Stata software (Version 15) was used for data analysis.

\section{RESULTS}

\section{ANALYSIS OF C.I.R.M. MEDICAL ASSISTANCE DATA 2017-2020}

In total, from January 1, 2017 to December 31, 2019, C.I.R.M. assisted 15,888 patients on board ships. As shown 
Table 1. Number of cases assisted from January 1 to June 30, from 2017 to 2020 by age and rank groups

\begin{tabular}{|c|c|c|c|c|c|c|c|c|}
\hline \multirow[t]{2}{*}{ Characteristics } & \multicolumn{2}{|l|}{2017} & \multicolumn{2}{|l|}{2018} & \multicolumn{2}{|l|}{2019} & \multicolumn{2}{|l|}{2020} \\
\hline & $N=2,419$ & $\begin{array}{l}\text { Frequency } \\
\text { (\%) }\end{array}$ & $N=2,444$ & $\begin{array}{l}\text { Frequency } \\
\text { (\%) }\end{array}$ & $N=2,694$ & $\begin{array}{l}\text { Frequency } \\
\text { (\%) }\end{array}$ & $N=3,924$ & $\begin{array}{l}\text { Frequency } \\
\text { (\%) }\end{array}$ \\
\hline \multicolumn{9}{|l|}{ Age } \\
\hline$\leq 30$ & 779 & 32.2 & 770 & 31.5 & 870 & 32.3 & 1200 & 30.57 \\
\hline $31-40$ & 735 & 30.4 & 760 & 31.1 & 787 & 29.2 & 1298 & 33.07 \\
\hline $41-50$ & 501 & 20.7 & 516 & 21.1 & 541 & 20.1 & 866 & 22.07 \\
\hline $51-60$ & 322 & 13.3 & 306 & 12.5 & 393 & 14.6 & 471 & 12.01 \\
\hline$\geq 61$ & 82 & 3.4 & 93 & 3.8 & 102 & 3.8 & 89 & 2.28 \\
\hline Mean \pm SD & \multicolumn{2}{|l|}{$37.8 \pm 12.1$} & \multicolumn{2}{|l|}{$37.7 \pm 11.5$} & \multicolumn{2}{|l|}{$37.5 \pm 10.6$} & \multicolumn{2}{|l|}{$37.7 \pm 10.7$} \\
\hline \multicolumn{9}{|l|}{ Rank } \\
\hline Deck officer & 409 & 16.9 & 428 & 17.5 & 493 & 18.3 & 679 & 17.3 \\
\hline Engine officer & 382 & 15.8 & 393 & 16.1 & 418 & 15.5 & 600 & 15.3 \\
\hline Deck rating & 593 & 24.5 & 574 & 23.5 & 657 & 24.4 & 1036 & 26.4 \\
\hline Engine rating & 539 & 22.3 & 530 & 21.7 & 585 & 21.7 & 848 & 21.6 \\
\hline Galley & 196 & 8.1 & 203 & 8.3 & 221 & 8.2 & 322 & 8.2 \\
\hline Others & 82 & 3.4 & 86 & 3.5 & 84 & 3.1 & 141 & 3.6 \\
\hline Unknown & 218 & 9 & 230 & 9.4 & 240 & 8.9 & 298 & 7.6 \\
\hline
\end{tabular}

SD - standard deviation

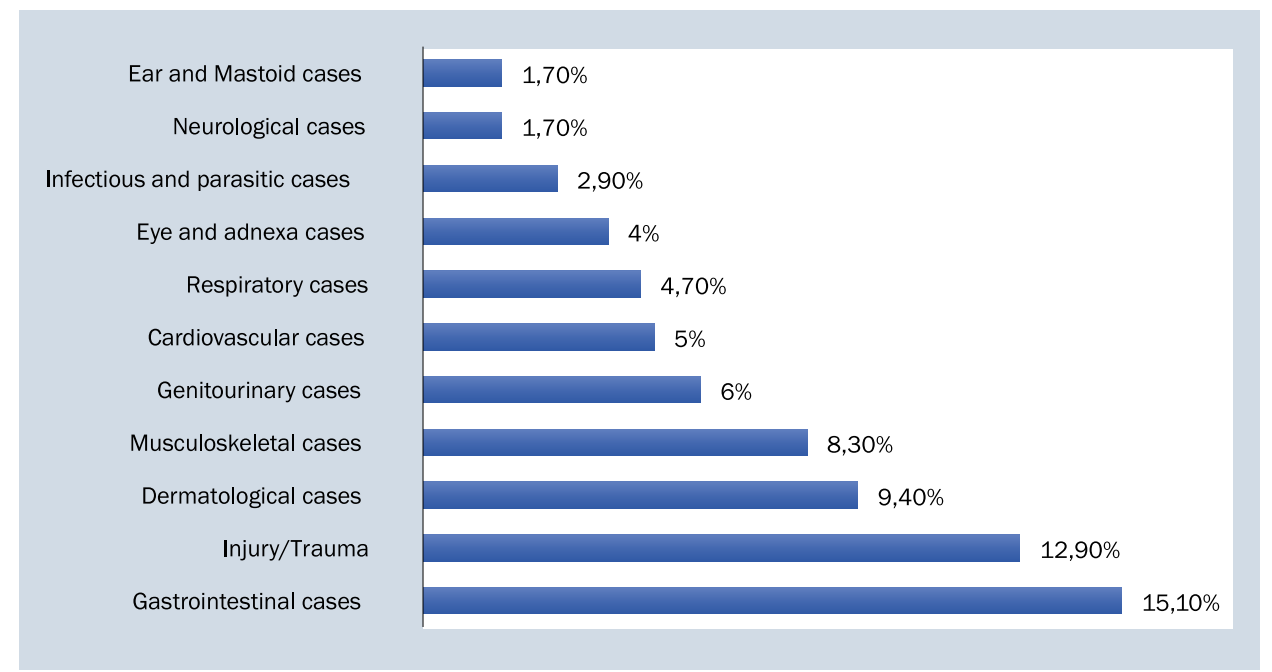

Figure 1. The distribution of diseases and injuries among seafarers with medical events from January 1, 2017 to June 30, 2020

in Table 1, from January 1, 2017, to June 30, 2020, C.I.R.M. assisted a total of 11,481 patients on board ships. $12.9 \%$ of the assisted seafarers $(1,486)$ suffered from medical conditions listed in chapter XIX (Injury, poisoning and certain other consequences of external causes) and chapter XX (External causes of morbidity and mortality) of the ICD-10 ${ }^{\text {th }}$ revision, whereas the remaining 9,995 (87.1\%) seafarers had medical conditions that are listed elsewhere in the
ICD-10 $10^{\text {th }}$ revision. Age and ranks of patients assisted by C.I.R.M. in the years 2017-2020 are summarised in Table 1. As shown below, the mean age \pm standard deviation of patients assisted by C.I.R.M. ranged from $37.8 \pm 12.1$ years in 2017 to $37.7 \pm 10.7$ years in 2020 . Almost all (98\%) of seafarers requesting medical advice were male.

Figure 1 shows the main pathologies affecting individuals assisted by C.I.R.M. in the first 6 months, i.e. from 
January 1 to June 30, of the years under evaluation, i.e. from 2017 to 2020. Gastrointestinal diseases $(n=1,731$, $15.10 \%)$ were the most commonly assisted health conditions, followed by trauma/injuries ( $n=1,486,12.9 \%$ ) and dermatological conditions ( $n=1,077,9.40 \%$ ). Musculoskeletal ( $n=949,8.3 \%)$, genitourinary $(n=705,6 \%)$, and cardiovascular $(n=577,5 \%$ ) diseases accounted for the fourth, fifth, and sixth cause of illness on board, respectively.

Centro Internazionale Radio Medico was contacted for 536 cases of respiratory diseases $(4.7 \%$ of the total number of cases); the mean age of patients assisted for respiratory conditions was $37.9 \pm 13.1$ years. Medical requests for respiratory system disorders almost tripled during the COVID-19 pandemic compared to the same period of

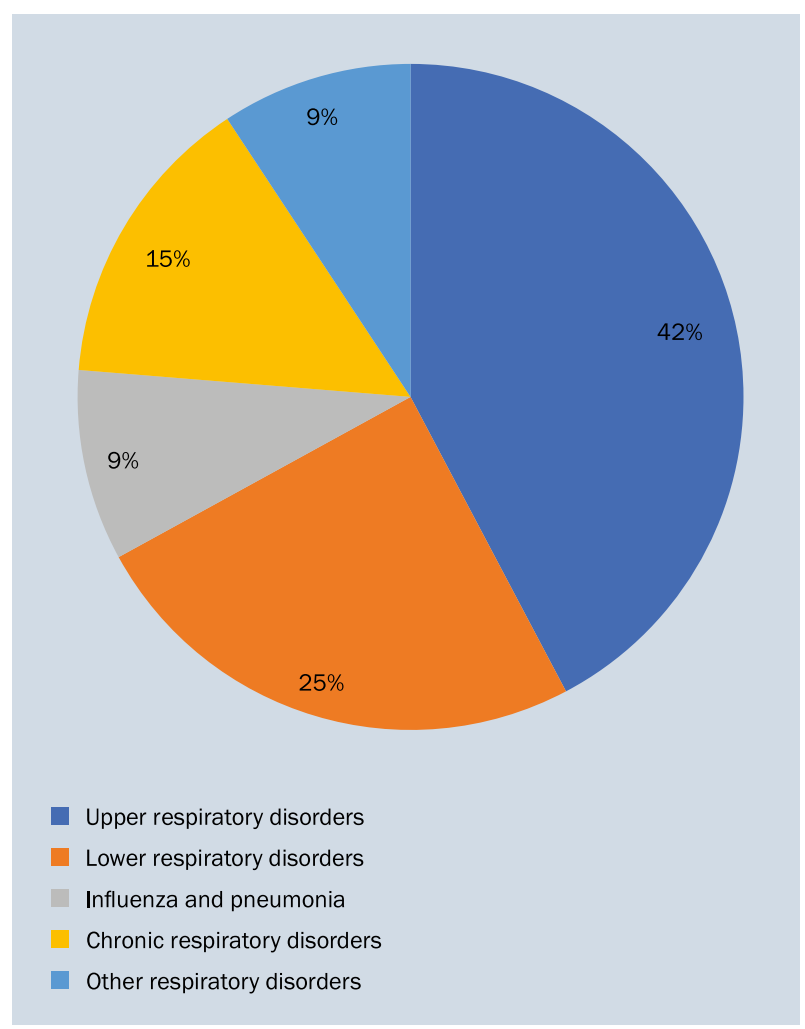

Figure 2. The distribution of respiratory system disorders among seafarers with medical events from January 1 to June 30, of the years 2017 to 2020
2017 (245 vs. 84). As indicated in Figure 2, the most frequently reported respiratory diseases were upper respiratory infections ( $n=225,42 \%$ ) such as pharyngitis, acute laryngitis, pharyngotonsillitis, and others. Lower respiratory system pathologies and chronic respiratory disorders were the second and third causes of medical requests on board ships and accounted for $25 \%(n=134)$ and $15 \%(n=80)$, of total respiratory disease cases, respectively. The remaining $18 \%$ were influenza and pneumonia $(n=49,9 \%)$ and other respiratory disorders $(n=48,9 \%)$.

\section{COMPARATIVE ANALYSIS OF C.I.R.M. MEDICAL ASSISTANCE DATA BEFORE AND DURING THE COVID-19 PANDEMIC}

The data on the comparative analysis of the number of cases assisted between January 1 and June 30 from 2017 to 2020 are summarised in Table 2 . A total of 11,481 patients were assisted on board ships and received 26,038 teleconsultations (an average of 2.2 calls per patient) over the 24 month period (the first 6 months of the four consecutive years from 2017 to 2020). As shown below, a remarkable increase in the number of cases was noticeable in the first 6 months of this year compared to the same period of 2017,2018 , and 2019. In other words, the number of assisted cases increased by $62 \%, 61 \%$, and $46 \%$ during the COVID-19 pandemic from January 1 to June 30, 2020 when compared to the same period of 2017,2018 , and 2019 , respectively.

As shown in Table 3, cases assisted for fever, cough, sore throat, and shortness of breath before (January 1 to June 30,2017 ) and during (January 1 to June 30,2020 ) the COVID-19 pandemic were compared. In the first 6 months of 2017 , out of 2,416 medical requests, 353 requests were for fever, 177 for cough, 92 for sore throat, and 56 for shortness of breath. In 2018, C.I.R.M. received a total of 2,444 requests for medical advice. Of these, 327 (13.4\%) requests were for fever, 154 (6.3\%) for cough, 83 (3.4\%) for sore throat and 56 (2.3\%) for shortness of breath. Whereas during the COVID-19 pandemic, i.e. from January 1 to June 30,2020 , a total of 3,924 medical requests, 832 cases for fever, 290 cases for cough, 220 cases for sore throat, and 149 cases for shortness of breath were received.

Table 2. Requests for medical advice received by C.I.R.M. from January-June 2017 to January-June 2020

\begin{tabular}{llllllll}
\hline Patients assisted & $\mathbf{2 0 1 7}$ & $\mathbf{2 0 1 8}$ & $\mathbf{2 0 1 9}$ & $\begin{array}{l}\text { Mean; } \\
\mathbf{2 0 1 7 - 2 0 1 9}\end{array}$ & $\mathbf{2 0 2 0}$ & $\begin{array}{l}\text { Frequency (\%) } \\
\text { variations }\end{array}$ \\
\hline No. of cases & 2,419 & 2,444 & 2,694 & 2,519 & 3,924 & +56 \\
No. of teleconsultations & 5,230 & 5,274 & 6,117 & 5,540 & 9,417 & +70 & +9 \\
Mean teleconsultations per case & 2.2 & 2.2 & 2.3 & 2.2 & 2.4 & 21.8 & +59
\end{tabular}


Table 3. Number of cases assisted at sea for common COVID-19 signs and symptoms during the first 6 months of 2017 to 2020

\begin{tabular}{|c|c|c|c|c|c|c|c|c|}
\hline \multirow[t]{2}{*}{ Symptom } & \multicolumn{2}{|l|}{2017} & \multicolumn{2}{|l|}{2018} & \multicolumn{2}{|l|}{2019} & \multicolumn{2}{|l|}{2020} \\
\hline & $N=2,419$ & $\begin{array}{l}\text { Frequency } \\
\text { (\%) }\end{array}$ & $N=2,444$ & $\begin{array}{l}\text { Frequency } \\
\text { (\%) }\end{array}$ & $N=2,694$ & $\begin{array}{l}\text { Frequency } \\
\text { (\%) }\end{array}$ & $N=3,924$ & $\begin{array}{l}\text { Frequency } \\
\text { (\%) }\end{array}$ \\
\hline Fever ${ }^{*}, \#{ }^{\wedge}$ & 353 & 14.6 & 327 & 13.4 & 466 & 17.3 & 832 & 21.2 \\
\hline Cough ${ }^{\wedge}$ & 177 & 7.3 & 154 & 6.3 & 140 & 5.2 & 290 & 7.4 \\
\hline Sore throat ${ }^{\star}, \#, \wedge$ & 92 & 3.8 & 83 & 3.4 & 119 & 4.4 & 220 & 5.6 \\
\hline Shortness of breath ${ }^{*} \#, \wedge$ & 56 & 2.3 & 56 & 2.3 & 35 & 1.3 & 149 & 3.8 \\
\hline
\end{tabular}

*P $<0.05$ for comparison of fever, cough, sore throat, and shortness of breath 2020 vs. 2017

$\# P<0.05$ for comparison of fever, cough, sore throat, and shortness of breath 2020 vs. 2018

${ }^{\wedge} \mathrm{P}<0.05$ for comparison of fever, cough, sore throat, and shortness of breath 2020 vs. 2019

Table 4. Requests for medical advice received by C.I.R.M. from January 1 to June 30, from 2017 to 2020 per month.

\begin{tabular}{|c|c|c|c|c|c|c|c|c|c|c|}
\hline \multirow[t]{2}{*}{ Month } & \multicolumn{5}{|c|}{ Patients assisted } & \multirow{2}{*}{$\begin{array}{l}\text { Frequency (\%) } \\
\text { variations* }\end{array}$} & \multicolumn{4}{|c|}{ Mean patients per day } \\
\hline & 2017 & 2018 & 2019 & Mean & 2020 & & 2017 & 2018 & 2019 & 2020 \\
\hline January & 414 & 404 & 478 & 432 & 506 & +17 & 13.4 & 13.0 & 15.4 & 16.3 \\
\hline February & 342 & 354 & 411 & 369 & 456 & +24 & 12.2 & 12.6 & 14.6 & 16.2 \\
\hline March & 401 & 404 & 437 & 414 & 651 & +57 & 12.9 & 13.0 & 14.1 & 21 \\
\hline April & 395 & 395 & 438 & 409 & 716 & +75.06 & 13.2 & 13.2 & 14.6 & 23.8 \\
\hline May & 414 & 422 & 475 & 437 & 834 & +90.85 & 13.4 & 13.6 & 15.3 & 26.9 \\
\hline June & 453 & 465 & 455 & 457 & 761 & +66.52 & 15.1 & 15.5 & 15.1 & 25.4 \\
\hline
\end{tabular}

*Frequency variations from the mean value (2017-2019) and 2020

Medical requests for fever during the first 6 months of the COVID-19 pandemic had doubled compared to the first half of 2017. From January 1 to June 30, 2020, C.I.R.M. received nearly 3 times more medical requests for fever than during the same period of 2018 and nearly 2 times more requests than in the same period of 2019. The difference in the number of medical requests for fever during the COVID-19 pandemic was statistically significant compared to the same period of $2017\left[\chi^{2}(1)=29.55, p<0.0005\right]$, $2018\left[\chi^{2}(1)=43.12, p<0.0005\right]$ and $2019\left[\chi^{2}(1)=10.25\right.$, $p=0.001]$. Medical requests for cough were more common in the first 6 months of this year compared to the same period from 2017 to 2019 . The increase in the number of teleconsultations for cough between the year 2020 and 2019 was found to be statistically significant $\left[\chi^{2}(1)=10.82\right.$, $p=0.001]$. There were nearly 3 times more medical requests for sore throat during the COVID-19 outbreak than during the first 6 months of 2017 and 2018 and nearly twice as many as in the same period of 2019. The increase in the frequency of medical requests for sore throat in the first 6 months of the COVID-19 pandemic was statistically significant in comparison to the same period of 2017 $\left[\chi^{2}(1)=9.10, p=0.002\right], 2018\left[\chi^{2}(1)=14.37, p=0.0002\right]$ and $2019\left[\chi^{2}(1)=3.98, p=0.04\right]$.

Requests for medical assistance due to shortness of breath were approximately 4 times more frequent during the first 6 months of this year compared to the same period of $2019\left[\chi^{2}(1)=34.15, p<0.0005\right]$. Differences for this medical problem were almost 3 times significantly higher than in the same period of $2017\left[\chi^{2}(1)=9.43\right.$, $p=0.002]$ and $2018\left[\chi^{2}(1)=9.84, p=0.002\right]$.

Table 4 presents the number of medical requests from January 1 to June 30, 2017 to 2020 on a monthly and average daily basis. As shown in this table, from May 2017 to May 2020, the number of assisted cases was doubled (it increased from 19\% to 39\%). In comparison to the same period of 2019, the highest increase was observed between March and May 2020 (Table 4).

Depending on the intensity of the symptoms, dedicated software assigned a triage tag to the first request for medical advice from a ship. The triage system aims to prioritise incoming medical requests and identify those who cannot wait to be consulted. A triage system is essential for sorting and classifying patients, determining their needs, and establishing treatment priorities. During outbreaks of infectious diseases, like COVID-19, it is used to separate patients likely to be infected with the pathogen of concern from those with other medical conditions. The system employed by C.I.R.M. uses four colour coded triage tags (white, green, yellow, and red) to classify the intensity of self-reported symptoms in those on board ships. Accordingly, the white tag indicates a mild case; the green tag indicates a moderate case; 
Table 5. The intensity of patients' symptoms helped during the first 6 months from January 1 to June 30, 2017-2020

\begin{tabular}{|c|c|c|c|c|c|}
\hline \multirow[t]{2}{*}{ Year } & \multirow[t]{2}{*}{ Triage tag } & \multicolumn{4}{|c|}{ Common symptoms of COVID-19 pandemic } \\
\hline & & Fever & Cough & Sore throat & Shortness of breath \\
\hline \multirow[t]{4}{*}{2017} & White & $104(29.5 \%)$ & $47(28.3 \%)$ & $44(47.8 \%)$ & $3(5.6 \%)$ \\
\hline & Green & $212(60 \%)$ & $109(65.7 \%)$ & $46(50 \%)$ & $23(42.6 \%)$ \\
\hline & Yellow & $33(9.4 \%)$ & $10(6 \%)$ & $2(2.2 \%)$ & $27(50 \%)$ \\
\hline & Red & $4(1.1 \%)$ & $0(0 \%)$ & $0(0 \%)$ & $1(1.9 \%)$ \\
\hline \multirow[t]{4}{*}{2018} & White & $62(19 \%)$ & $29(20.4 \%)$ & $21(26.6 \%)$ & $1(2.2 \%)$ \\
\hline & Green & $236(72.8 \%)$ & $106(74.7 \%)$ & $54(68.4 \%)$ & $26(57.8 \%)$ \\
\hline & Yellow & $23(7 \%)$ & $7(4.9 \%)$ & $4(5 \%)$ & $16(35.6 \%)$ \\
\hline & Red & $3(0.93 \%)$ & $0(0 \%)$ & $0(0 \%)$ & $2(4.4 \%)$ \\
\hline \multirow[t]{4}{*}{2019} & White & $86(18.5 \%)$ & 31 (22\%) & $18(17.6 \%)$ & $2(4.4 \%)$ \\
\hline & Green & 331 (71\%) & 80 (57\%) & 73 (71.6\%) & $18(40 \%)$ \\
\hline & Yellow & 47 (10\%) & $28(20 \%)$ & $10(9.8 \%)$ & 22 (48.9\%) \\
\hline & Red & $2(0.43 \%)$ & $1(0.71 \%)$ & $1(0.98 \%)$ & $3(6.7 \%)$ \\
\hline \multirow[t]{4}{*}{2020} & White & 163 (19.6\%) & 40 (13.8\%) & $50(22.7 \%)$ & $9(6 \%)$ \\
\hline & Green & 611 (73.5\%) & 222 (76.6\%) & $158(71.8 \%)$ & $94(63 \%)$ \\
\hline & Yellow & $53(6.4 \%)$ & 27 (9.3\%) & $11(5 \%)$ & $40(26.8 \%)$ \\
\hline & Red & $4(0.48 \%)$ & $1(0.35 \%)$ & $1(0.46 \%)$ & $6(13.3 \%)$ \\
\hline
\end{tabular}

the yellow tag indicates an urgent case, and the red tag indicates a severe case. As shown in Table 5, most of the C.I.R.M. assisted cases were coded with white or green tags. For example, $73.5 \%$ (611) of fever cases reported in the first 6 months of this year were classified as moderate cases (Table 5).

\section{DISCUSSION}

There were a total of 11,481 requests for assistance to C.I.R.M. due to occupational injuries and illnesses over the 24 month period (in the first 6 months of 2017 until 2020). In terms of the types of pathologies requiring medical advice, gastrointestinal disorders and trauma/injuries were among the most commonly reported medical conditions occurring on board during the study period and were responsible for $15.10 \%$ and $12.90 \%$ of all requests, respectively. The findings reported in this study concerning injuries are in line with the Polish TMAS report [11]. A previous research study conducted by C.I.R.M. has shown that digestive system disorders were the most commonly reported causes of illness on board during the periods: 1952-1961, 1962-1971, and 1972-1981. After the 1980s, these pathologies held the second place [12]. The present study has reported that gastrointestinal cases were the number one cause of pathologies on board during the study period. These findings are consistent with those reported by the Swedish TMAS [13]. A higher prevalence of gastrointestinal conditions could be attributed to various factors, such as ingesting contaminated food or water, and contact with contaminated environment. Dermatological and musculoskeletal cases were the third and fourth most common reason for seeking help from C.I.R.M doctors during the study period.

In this study, our attention was focused on the cases assisted in the first 6 months of the COVID-19 pandemic (January-June 2020). Considering the fact that on board cargo ships asking for telemedical advice a definite COVID-19 diagnosis cannot be made, we have investigated the occurrence of common signs of the coronavirus infection, including fever, cough, sore throat, and shortness of breath. Accordingly, a higher number of cases assisted on board during COVID-19 pandemic (3,924 cases) than during the same months of the year before the outbreak (2,694 cases) was noticeable. In the first 6 months of this year, a higher number of seafarers with fever, cough, sore throat, and shortness of breath asked for telemedical advice compared to the years from 2017 to 2019. This could indicate a possible occurrence of some COVID-19-like pathologies on board ships but might as well be a sign of fear among seafarers and/or ship passengers of having developed the COVID-19 infection.

A study conducted on the Diamond Princess cruise ship reported that approximately 3,700 passengers and crew members were quarantined on February 3, 2020, in the port of Yokohama, Japan. By the end of the quarantine, nearly 700 coronavirus cases had been confirmed by laboratory test [14]. The same study revealed that the first verified COVID-19 case in a crew member occurred in food service workers [14]. 
As already mentioned a higher number of requests for assistance to the TMAS services in the time of COVID-19 pandemic may indicate a growing number of COVID-19 infections among seafarers, but on the other hand, it might also be a sign of panic and conviction that fever and shortness of breath are inevitably a sign of COVID-19 infection. Although shortness of breath and fever are the very common symptoms of a coronavirus infection, it is difficult to make a definite diagnosis from ashore unless quick diagnostic tests are available on board. There are at least several other pulmonary pathologies, including asthma, chronic obstructive pulmonary disorders and community-acquired pneumonia, which can cause shortness of breath, fever, cough, and dyspnoea.

In this particular situation, it is essential to take early warning symptoms if one of the crew members is sick. In this time of local and global distress, people on board ships who develop emergency warning signs for coronavirus should get medical attention as soon as possible. It is impossible to carry highly sensitive diagnostic systems for COVID-19 on board due to the costs involved and the difficulties in handling these systems by non-experts, e.g. ship officers. Based on our own experience, the availability of a pulse oximeter on board has allowed us to manage several doubtful cases. With an approach consisting of starting oxygen therapy in patients showing relevant respiratory symptoms and blood oxygen level below $92 \%$, we could effectively manage all cases of pulmonary pathologies reported to C.I.R.M. without losing any of the patients.

Centro Internazionale Radio Medico statistics show that cardiovascular and respiratory system conditions are the sixth and seventh most common causes of illness on board (Fig. 1). Several recent studies related to coronavirus infection have reported that people with underlying illnesses, particularly chronic illnesses such as cardiovascular disease, respiratory problems, and adults over 65 years of age, are at an increased risk of a severe course of the COVID-19 pandemic once infected $[15,16]$. Therefore, a crew member with underlying health conditions like hypertension, diabetes, chronic obstructive pulmonary diseases, or cardiovascular disease should receive more medical attention. Potential risk areas on board should be identified, adequate health education must be provided to crew members and passengers, and environmental sanitation should be carried out correctly. Similarly, a study conducted on board a cruise vessel reported that the crew dining area was the primary area of congregation for the crew, and 15 out of 20 , confirmed cases in crew members occurred in food service workers [14]. Hence, dining areas and the crew member living places, especially the galley, should be sanitised on a regular basis to prevent transmission. Moreover, all crew members should maintain standard recommendations to prevent the spread of COVID-19 infection on board. These include covering the mouth and nose when coughing and sneezing, proper handwashing, cooking meat and eggs thoroughly, avoiding close contact with any crew member who shows symptoms of a respiratory disease.

Seafaring is one of the most hazardous occupations as far as personal health and occupational safety are concerned. Additionally, ships are one of the most crowded environments, where apart from injuries/traumas, seafarers are continuously exposed to infectious agents such as those transmissible by direct contact or droplets [17]. To prevent this novel and deadly pandemic (COVID-19 infection), any crew member who has had close contact with a confirmed case should quarantine and monitor his/her symptoms. For any early warning signs like fever, cough, shortness of breath, sore throat, and dyspnoea, the contact of a TMAS for proper treatment of the case is strongly recommended.

\section{CONCLUSIONS}

During the COVID-19 pandemic, telemedical advice on board was required for a higher number of seafarers. Fever, sore throat, and dyspnoea were the primary reasons for the more frequent requests for maritime telemedical advice, which were remarkably increased during the coronavirus outbreak. Close follow-up, regular health education on preventing coronavirus, using personal protective equipment, and adequate environmental hygiene could help minimise the potential risk factors for the COVID-19 transmission. Standard precautions such as frequent handwashing, covering the mouth and nose when coughing and sneezing, avoiding close contact with any crew member showing early warning symptoms should be applied by all crew members regardless of suspected or confirmed cases.

\section{ACKNOWLEDGEMENTS}

This work was supported by a grant No. 1508 from the ITF Seafarers' Trust, London, United Kingdom.

\section{CONFLICT OF INTEREST}

The authors declare that they have no conflicts of interest.

\section{REFERENCES}

1. de Wit E, van Doremalen N, Falzarano D, et al. SARS and MERS: recent insights into emerging coronaviruses. Nat Rev Microbiol. 2016; 14(8): 523-534, doi: 10.1038/nrmicro.2016.81, indexed in Pubmed: 27344959.

2. Mizumoto $\mathrm{K}$, Chowell G. Transmission potential of the novel coronavirus (COVID-19) onboard the diamond Princess Cruises Ship, 2020. Infect Dis Model. 2020; 5: 264-270, doi: 10.1016/j. idm.2020.02.003, indexed in Pubmed: 32190785.

3. Glass C, Cash J, Mullen J. Coronavirus Disease (COVID-19). Family Practice Guidelines. 2020, doi: 10.1891/9780826153425.0016b. 
4. ILO. ILO Sectoral Brief: COVID-19 and maritime shipping and fishing, 2020; No. March, pp. 1-8.

5. Takeuchi I. COVID-19 first stage in Japan - how we treat 'Diamond Princess Cruise Ship' with 3700 passengers? Acute Med Surg. 2020; 7(1): e506, doi: 10.1002/ams2.506, indexed in Pubmed: 32313661.

6. Rocklöv J, Sjödin H, Wilder-Smith A. COVID-19 outbreak on the Diamond Princess cruise ship: estimating the epidemic potential and effectiveness of public health countermeasures. J Travel Med. 2020; 27(3), doi: 10.1093/jtm/taaa030, indexed in Pubmed: 32109273.

7. Sagaro GG, Amenta F. Past, present, and future perspectives of telemedical assistance at sea: a systematic review. Int Marit Health. 2020; 71(2): 97-104, doi: 10.5603/IMH.2020.0018, indexed in Pubmed: 32604452.

8. Amenta DTF, Tveito A., TELEMEDICINE AT SEA: COMMUNICATIONAL CHALLENGES, ISfTeH e-Journal, 2007; pp. 219-222 [Online]. https://www.isfteh.org/media/med_e_tel_2007.

9. Mahdi SS, Amenta F. Eighty years of CIRM. A journey of commitment and dedication in providing maritime medical assistance. Int Marit Health. 2016; 67(4): 187-195, doi: 10.5603/IMH.2016.0036, indexed in Pubmed: 28009394.

10. WHO. International statistical classification of diseases and related health problems:10th revision. 2016; vol. 1, no. Fifth edition 2016 [Online]. www.who.int/about/licensing/copyright_form/en/index.html.

11. Szafran-Dobrowolska J, Renke M, Wołyniec W. Telemedical Maritime Assistance Service at the University Center of Maritime and Tropi- cal Medicine in Gdynia. The analysis of 6 years of activity. Med Pr. 2020; 71(2): 121-125, doi: 10.13075/mp.5893.00897, indexed in Pubmed: 31929519.

12. Amenta F, Dauri A, Rizzo N. Organization and activities of the International Radio Medical Centre (CIRM). J Telemed Telecare. 1996; 2(3): 125-131, doi: 10.1258/1357633961929907, indexed in Pubmed: 9375045.

13. Westlund K, Attvall S, Nilsson R, et al. Telemedical Maritime Assistance Service (TMAS) to Swedish merchant and passengers ships 1997-2012. Int Marit Health. 2016; 67(1): 24-30, doi: 10.5603/ IMH.2016.0006, indexed in Pubmed: 27029926.

14. Kakimoto K, Kamiya H, Yamagishi T, et al. Initial Investigation of Transmission of COVID-19 Among Crew Members During Quarantine of a Cruise Ship - Yokohama , Japan , February 2020, 69, 11, 312-313.

15. Guo $Y$, et al. The origin, transmission and clinical therapies on coronavirus disease 2019 (COVID-19) outbreak - an update on the status. 2020: 1-10.

16. CDC. People Who Are at Higher Risk for Severe Illness | CDC. https:// www.cdc.gov/coronavirus/2019-ncov/need-extra-precautions/ people-at-higher-risk.html?CDC_AA_refVal=https $\% 3 \mathrm{~A} \% 2 \mathrm{~F} \% 2 \mathrm{Fwww}$. cdc.gov\%2Fcoronavirus\%2F2019-ncov\%2Fspecific-groups\%2Fpeople-at-higher-risk.html (accessed Apr. 09, 2020).

17. Rashid H, Haworth E, Shafi S, et al. Pandemic influenza: mass gatherings and mass infection. Lancet Infectious Diseases. 2008; 8(9): 526-527, doi: 10.1016/s1473-3099(08)70186-5. 